\title{
ENGINEERING HIGH-SPEED, ULTRA-SMOOTH REACTIVE PHASE GLASS ETCHING IN AN INDUCTIVELY COUPLED PLASMA
}

Chenchen Zhang, Gokhan Hatipoglu, and Srinivas Tadigadapa

Department of Electrical Engineering, Pennsylvania State University, USA

\begin{abstract}
In this paper we report a modified inductively coupled plasma reactive ion etch (ICP-RIE) tool and using $\mathrm{NF}_{3}$ and $\mathrm{H}_{2} \mathrm{O}$ gases generated plasma species as the primary chemistry for glass etching. Using this technique we have been able to achieve etch rates as high as $0.81 \mu \mathrm{m} / \mathrm{min}$ and a surface smoothness $\left(R_{a}\right)$ of $\sim 6 \AA$ for quartz and $0.68 \mu \mathrm{m} / \mathrm{min}$ and a surface smoothness of $\sim 4 \AA$ for borosilicate glass. The modified etch chamber described here allows for a systematic study of the glass etching process with capability to tune the physical and chemical (species dissociation) components during the etching process.
\end{abstract}

\section{INTRODUCTION}

Dating back to 1980 's, silicon dioxide plasma etching processes were originally developed for realizing features for microelectronics applications such as interconnect vias, waveguides, phase shift masks, etc [1, 2, 3]. The primary focus of this earlier work was improving the selectivity of $\mathrm{SiO}_{2}$ with respect to silicon [4], reducing gate oxide damage [5], etc. The advent of microelectromechanical systems (MEMS) and microsystems in the last decade, has markedly shifted the research in this field towards the development of silicon dioxide etching processes with high etch rate, smooth etched profiles, high etch selectivity to mask materials, high anisotropy, uniformity within a pattern and across the wafer, etc for applications in microfluidics [6], microsensors [7] and lab-on-a-chip applications.

ICP-RIE process is widely used in microfabrication because it allows to independently control plasma density (controlled by source power) and energy of etchant ions (controlled by substrate power). As a result, it provides stable high density plasma even in a relative low pressure environment $\left(10^{-3}\right.$ Torr $-10^{-4}$ Torr $)$. There have been several spurts of research developments in the field leading to reported etch rates of glass in the range of $0.6-0.9$ $\mu \mathrm{m} / \mathrm{min}$ under ICP-RIE [8 - 10].

Conventional ICP-RIE is a physical/chemical mixed etching process. Usually, inert gases such as xenon and argon are used in process to physically bombard silicon dioxide [8], while halogen molecules are used in the process to affect chemical reaction with silicon dioxide. Due to the high inert gas content and long mean free path and high-energy typically used in a conventional ICP-RIE, glass etching is dominated by physical etching processes [8-10]. In this paper, we present a novel modification to the plasma etch chamber with a gas diffuser ring which is able to further tune the physical and chemical components during the etching process.

\section{EXPERIMENT SETUP}

\section{Sample Preparation}

$500 \mu \mathrm{m}$ thick, double-side polished 4 inch borosilicate and quartz wafers were cleaned in Nanostrip ${ }^{\circledR}$ for 30 mins and then deposited with $15 \mathrm{~nm}$ chromium and $150 \mathrm{~nm}$ gold seed metal layers using an evaporator. Wafers were patterned by photoresist AZ 1127 and $25 \%$ Microposit $^{\mathrm{TM}} 351$ developer to form $3.5 \mu \mathrm{m}$ thick photoresist pattern. $2-3 \mu \mathrm{m}$ thick nickel was electroplated to form the hard mask with feature widths ranging from $100 \mu \mathrm{m}$ $1000 \mu \mathrm{m}$.

\section{Modified Etching Chamber}

Alcatel AMS 100 ICP-RIE etch tool was modified in this work. Instead of conventionally feeding gases through the ICP source, a stainless steel gas diffuser ring was attached to the metal plate of the mechanical clamping plate of the etcher and is used to locally introduce $\mathrm{NF}_{3}$ and $\mathrm{H}_{2} \mathrm{O}$ vapor gases in the vicinity of the wafer as shown in Figure 2. The substrate bias power drives the high energy ions from the plasma towards the $\mathrm{NF}_{3}$ and $\mathrm{H}_{2} \mathrm{O}$ gas cloud near the glass wafer and breaks down the highly unstable $\mathrm{NF}_{3}$ gas into $\mathrm{NF}_{\mathrm{x}}$ radicals - this is a radical departure from when the $\mathrm{NF}_{3}$ gas is fed through the ICP chamber where the gas is completely fragmented into $\mathrm{N}$ and $\mathrm{F}$ radicals and ions and is not as effective in etching glass substrates. An in-situ residual gas analyzer (RGA) is connected to the reactor chamber in order to analyze the reaction and product species, stylus profilometer (P-16, Tencor $^{\circledR}$ ) and AFM was used to characterize the smoothness of the obtained etch topography and an ex-situ X-ray photoelectron spectroscopy (XPS) was used to analyze the atomic and molecular species on the surface of the etched glass regions. Ring diffused $\mathrm{NF}_{3}$ and $\mathrm{H}_{2} \mathrm{O}$ vapor gases are controlled by separate mass flow controllers. Available ranges of power and gas flow rates of individual gases for the modified etch system are listed in Table 1.
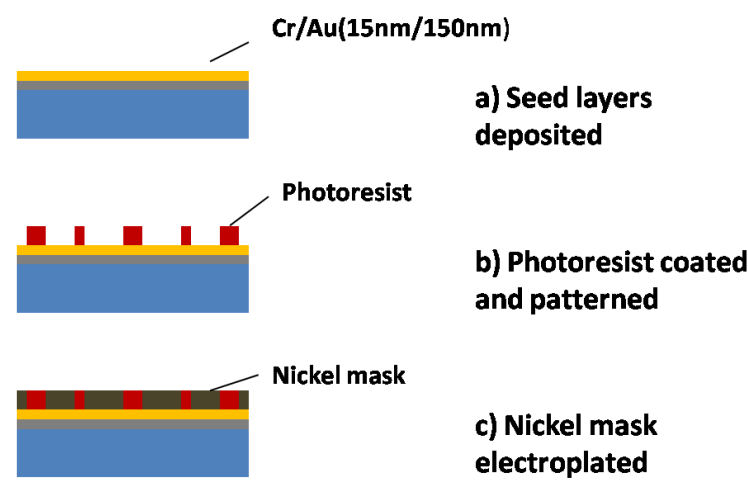
c) Nickel mask
electroplated

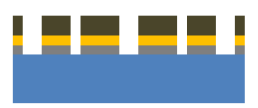

d) PR\&Au\&Cr stripped

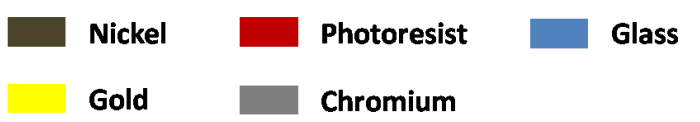

Figure1: Samples process flow

\section{RESULTS AND DISSCUSSIONS \\ Chamber Modification Analysis using RGA Data}

Gas species were detected and characterized using a quadrupole residual gas analyzer (RGA) ExTorr $^{\circledR}$ XT100 connected directly to the modified etch chamber. RGA data was acquired for three different conditions: (i) background gases, (ii) 
$\mathrm{NF}_{3}$ and $\mathrm{Ar}$ introduced as the primary plasma source gases from top of the chamber and (iii) $\mathrm{SF}_{6} / \mathrm{NF}_{3} / \mathrm{H}_{2} \mathrm{O}$ gases with $\mathrm{SF}_{6}$ as the primary plasma source gas introduced from top and $\mathrm{NF}_{3} / \mathrm{H}_{2} \mathrm{O}$ diffused from ring. Figure $3 \mathrm{a}$ ) shows that water vapor, nitrogen and oxygen gases are detectable in the initial chamber which is pumped down to $10^{-6}$ Torr. Clearly no $\mathrm{NF}_{\mathrm{x}}$ gas species are generated if $\mathrm{NF}_{3}$ is used as the plasma source gas as can be seen in Figure $3 b$ ). Finally, Figure $3 \mathrm{c}$ ) shows that $\mathrm{NF}_{\mathrm{x}}$ are generated with many other active ions and radicals in diffuser ring system.

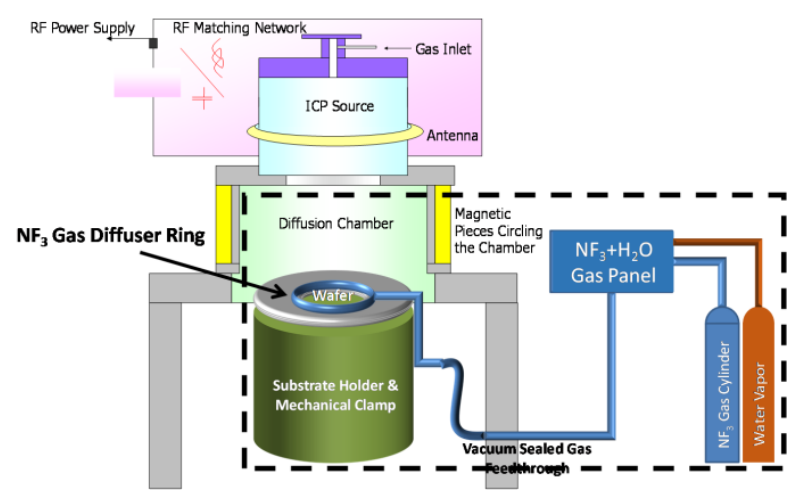

Figure 2: Schematic illustration of the modified ICP-RIE systems with ring-diffuser system. Inset shows the photos the actual stainless steel showerhead nozzles.

\begin{tabular}{|c|c|c|}
\hline & $\begin{array}{l}\text { Relevant Process } \\
\text { Parameters }\end{array}$ & Range \\
\hline \multirow{3}{*}{ ICP Source Gases } & $\mathrm{SF}_{6}$ & $0-200 \mathrm{sccm}$ \\
\hline & Ar & $0-100 \mathrm{sccm}$ \\
\hline & $\mathrm{O}_{2}$ & $0-100 \mathrm{sccm}$ \\
\hline \multirow{5}{*}{ Ring Diffuser Gases } & $\mathbf{N F}_{\mathbf{3}}$ & $0-250 \mathrm{sccm}$ \\
\hline & $\mathrm{H}_{2} \mathrm{O}$ & $0-300 \mathrm{sccm}$ \\
\hline & ICP Power & $0-3000 w$ \\
\hline & SubstratePower & $0-600 w$ \\
\hline & Pressure & $0-0.1 \mathrm{mbar}$ \\
\hline
\end{tabular}

Table 1. Summary on capability of modified etching system

$\mathrm{SF}_{6} / \mathrm{NF}_{3} / \mathrm{H}_{2} \mathrm{O}$ based etching is compared with $\mathrm{SF}_{6}$-only plasma etching. The results are shown in Table.2. Wafers were processed using $2000 \mathrm{~W}$ source power and $400 \mathrm{~W}$ substrate power. The substrate temperature was set to $20{ }^{\circ} \mathrm{C}$ and the source-substrate distance was set to $120 \mathrm{~mm}$. Wafers were etched for 15 minutes. Four different etch-gas compositions are demonstrated for borosilicate glass and quartz etching respectively. Processes \#1 and \#3 were developed with diffuser ring system while processes \#2 and \#4 are listed for comparison with conventional $\mathrm{SF}_{6}$ plasma etching process. To make comparisons between the two entirely different etch approaches we adjusted the flow range of the various gases in experiments \#1 and \#2, and \#3 and \#4 to result in identical chamber pressure. Same plasma power and pressure in the two different etches helps easier comparison since the plasma density and ion bombardment rates in the two cases should be comparable and any differences can be discussed in terms of achievable chemical etching between diffuser ring system and conventional etching. Table. 2 shows that the etch rate of borosilicate glass and quartz glass in diffuser ring system is higher by $33 \%$ and $31 \%$ as compared to conventional etching method. Furthermore, we measured the average etched surface roughness $(\mathrm{Ra})$ using precision scans of the region using the profilometer stylus which has a resolution in the Angstrom range and followed the most promising results with Atomic Force Microscope (AFM) scans. For both glass and quartz substrates the achieved surface smoothness of the etched areas from the ring diffuser set-up was an order of magnitude better than conventional etch process.
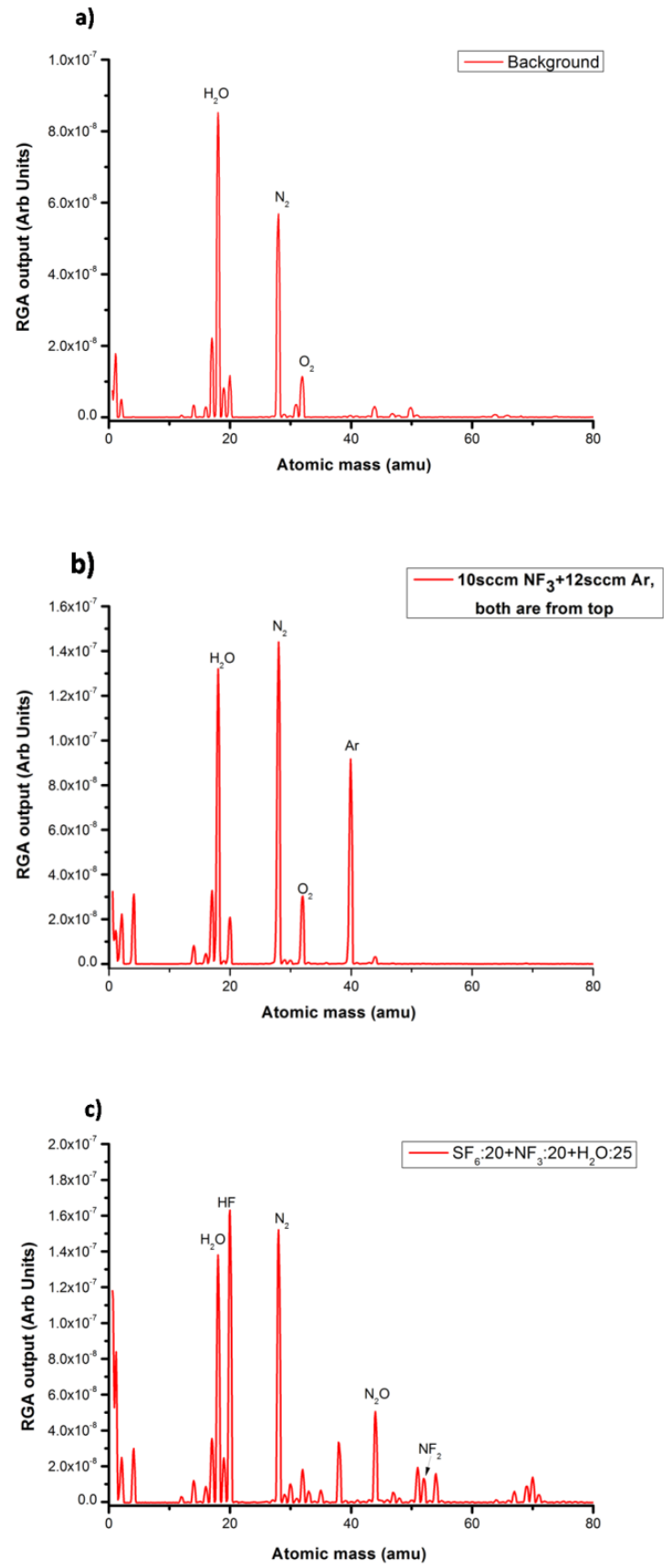

Figure.3: Residue gases analysis on a)background, b)top $10 \mathrm{sccm}$ $\mathrm{NF}_{3}+$ top $12 \mathrm{sccm} \mathrm{Ar}, \mathrm{c}$ ) top $20 \mathrm{sccm} \mathrm{SF}_{6}+$ ring $20 \mathrm{sccm} \mathrm{NF}_{3}+$ ring $25 \mathrm{sccm} \mathrm{H}_{2} \mathrm{O}$ 
In fact the achieved smoothness of the order of few Angstroms has not been reported before. The voltage shown in the table represents the electrical potential between plasma and substrate, which is read out on Alcatel AMS 100 tool automatically. The potential in the $\mathrm{SF}_{6}$-only plasma is $\sim 5 \%$ larger than for the $\mathrm{NF}_{3}+\mathrm{H}_{2} \mathrm{O}$ ring diffuser plasma conditions indicating that the energy of the bombarding ions should be higher in the conventional $\mathrm{SF}_{6}$ based etching. In spite of this situation, both the etch rate and the surface smoothness conditions are improved in the ring diffuser etch. RGA data, from Figure.3(c), suggests the plasma conditions in ring diffused gases are able to produce active radicals and ions such as $\mathrm{NF}_{\mathrm{x}}$, $\mathrm{NO}$ and $\mathrm{HF}$ etc. The formation of active chemicals at vicinity of the wafer increases the effects of chemical etching and optimizes the etching performances. AFM shows surface roughness ( $\mathrm{Ra}$ ) of $\# 1$ and \#3 recipe samples are $4 \AA$ and $6 \AA$. Statistical analysis of AFM scanning on \#3 recipe sample is shown in Figure 4(a). The SEM picture at right side of Figure 4 presents the cross section and trench bottom under ring diffused $\mathrm{SF}_{6} / \mathrm{NF}_{3} / \mathrm{H}_{2} \mathrm{O}$ based etching.

\begin{tabular}{|c|c|c|c|c|c|c|c|}
\hline $\begin{array}{c}\text { Borosi } \\
\text { licate }\end{array}$ & $\begin{array}{c}\mathrm{SF}_{6} \\
(\mathrm{sccm})\end{array}$ & $\begin{array}{c}\mathrm{NF}_{3} \\
(\mathrm{sccm})\end{array}$ & $\begin{array}{c}\mathrm{H}_{2} \mathrm{O} \\
(\mathrm{sccm})\end{array}$ & $\begin{array}{c}\text { Pressure } \\
(\mathrm{m} \text { Torr })\end{array}$ & $\begin{array}{c}\text { Voltage } \\
(\mathrm{V})\end{array}$ & $\begin{array}{c}\text { Etching rate } \\
(\mu \mathrm{m} / \mathrm{min})\end{array}$ & $\begin{array}{c}\text { Roughness } \\
(\hat{\AA})^{*}\end{array}$ \\
\hline$\# 1$ & 20 & 20 & 25 & 3 & 73 & 0.68 & 0.7 \\
\hline$\# 2$ & 60 & 0 & 0 & 3 & 78 & 0.51 & 9.4 \\
\hline Quartz & $\begin{array}{c}\mathrm{SF}_{6} \\
(\mathrm{sccm})\end{array}$ & $\begin{array}{c}\mathrm{NF}_{3} \\
(\mathrm{sccm})\end{array}$ & $\begin{array}{c}\mathrm{H}_{2} \mathrm{O} \\
(\mathrm{sccm})\end{array}$ & $\begin{array}{c}\text { Pressure } \\
(\mathrm{mbar})\end{array}$ & $\begin{array}{c}\text { Voltage } \\
(\mathrm{V})\end{array}$ & $\begin{array}{c}\text { Etching rate } \\
(\mu \mathrm{m} / \mathrm{min})\end{array}$ & $\begin{array}{c}\text { Roughness } \\
(\AA)\end{array}$ \\
\hline$\# 3$ & 60 & 100 & 50 & 9 & 78 & 0.81 & 0.6 \\
\hline$\# 4$ & 200 & 0 & 0 & 9 & 82 & 0.62 & 21.9 \\
\hline
\end{tabular}

Table 2: Comparison between $\mathrm{SF}_{6} / \mathrm{NF}_{3} / \mathrm{H}_{2} \mathrm{O}$ based etching and single $\mathrm{SF}_{6}$ plasma etching. "Roughness is measured by profilometer

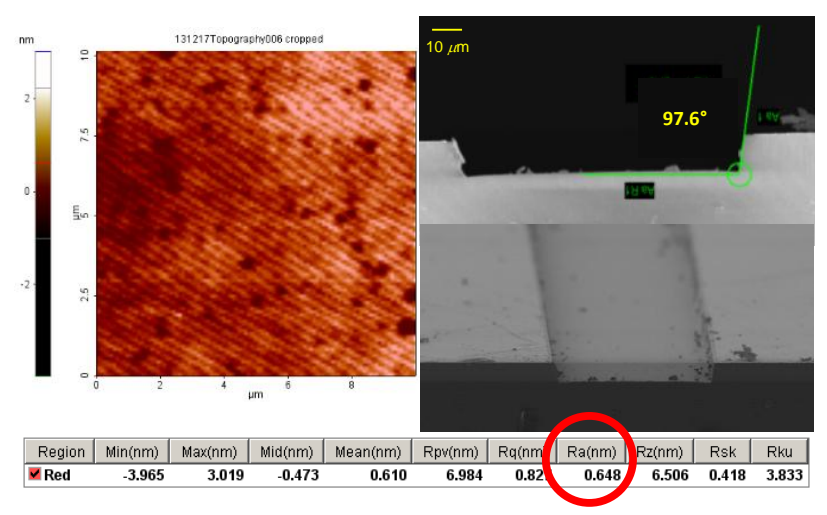

Figure 4: (a) AFM image of the smoothest substrate obtained with ring active etch. (b) The inset shows the SEM picture of the etch region cross section

\section{Etch Rate with Diffuser Ring}

Using the ring diffuser system, we were able to achieve $0.81 \mu \mathrm{m} / \mathrm{min}$ and $0.68 \mu \mathrm{m} / \mathrm{min}$ etch rates for quartz and borosilicate glass respectively. Fig. 5 shows the various process gas flow rates explored and clearly shows that although the two substrates predominantly consist of $\mathrm{SiO}_{2}$ in composition, the optimal etching conditions for quartz and borosilicate glass are quite different. This is to be expected since they have different structure and material composition. Borosilicate contains $80.6 \% \mathrm{SiO}_{2}, 12.6 \% \mathrm{~B}_{2} \mathrm{O}_{3}$, $4.2 \% \mathrm{Na}_{2} \mathrm{O}, 2.2 \% \mathrm{Al}_{2} \mathrm{O}_{3}, 0.04 \% \mathrm{Fe}_{2} \mathrm{O}_{3}, 0.1 \% \mathrm{CaO}, 0.05 \% \mathrm{MgO}$, and $0.1 \% \mathrm{Cl}$, while quartz is pure silicon oxide.
Borosilicate contains more non-bridging oxygen bond than quartz in $\left(\mathrm{SiO}_{4}\right)^{4-}$ tetrahedral network structure. The most important impurity of borosilicate is boron atom. Since this impurity has on less electron to contribute to the covalent bonding than does silicon. The missing electron induced by such impurity in the center of tetrahedron results in the elimination of bridging oxygen ions. In the case of the elimination of a bridging oxygen bond, a non-bridging oxygen is created which tends to weaken the network and thus should improve the etch rate [11]. On the other hand, alumina and alkalis components in borosilicate are hard non-volatile materials, which slows down the etch rate. Table 3 lists the XPS date on borosilicate glass surface composition for different process conditions. The obtained data shows a significantly larger percentage of surface aluminum and sodium content for the wafers etched with $80 \mathrm{sccm} \mathrm{NF}_{3}$ flow rate than in the case of $20 \mathrm{sccm}$ flow rate and explains the slower etch rate obtained for the former condition.

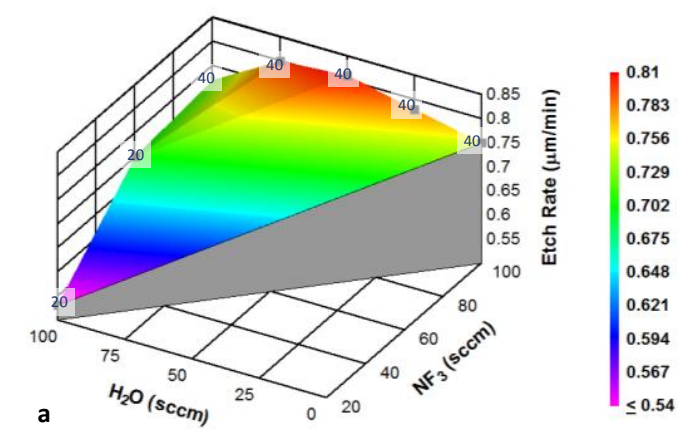

Label Values: $\mathrm{SF}_{6}$ Flow (sccm)

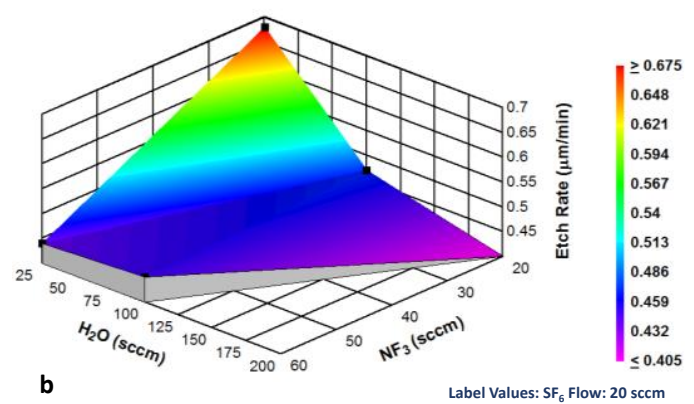

Figure 5: Etch rate as a function of $\mathrm{SF}_{6}, \mathrm{NF}_{3}$, and $\mathrm{H}_{2} \mathrm{O}$ flow rates for (a) Fused Quartz and (b) Borofloat ${ }^{\circledR}$ wafers. SF $F_{6}$ flow rate is 20 sccm for all the points shown in (b).

\begin{tabular}{|c|c|c|c|c|c|c|c|c|}
\hline & $\mathrm{Si} 2 \mathrm{~s}$ & $01 \mathrm{~s}$ & F 1s & $\mathrm{Na}$ 1s & B 1s & Al $2 \mathrm{~s}$ & $\mathrm{~K} 2 \mathrm{~s}$ & $\mathrm{Ni} 2 \mathrm{p}$ \\
\hline $\begin{array}{l}\text { Ring active etch- } \\
20 \mathrm{sccm} \mathrm{NF}{ }_{3}\end{array}$ & 20.7 & 51.696 & 15.751 & 7.526 & 2.105 & 2.22 & $\mathrm{ND}^{*}$ & $\mathrm{ND}^{*}$ \\
\hline $\begin{array}{l}\text { Ring active etch- } \\
80 \mathrm{sccm} \mathrm{NF}_{3}\end{array}$ & 4.483 & 6.487 & 56.448 & 20.946 & 4.144 & 5.102 & 1.887 & $\mathrm{ND}^{*}$ \\
\hline $\begin{array}{l}\text { Unprocessed } \\
\text { Borofloatwafer }\end{array}$ & 27.91 & 66.92 & $\mathrm{ND}^{*}$ & 0.46 & 4.69 & $\mathrm{ND}^{*}$ & $\mathrm{ND}^{*}$ & $\mathrm{ND}^{*}$ \\
\hline
\end{tabular}

Table 3: Approximate atomic percent calculations from XPS surveys for 2 different etch cases. All values are in percent. * ND: Not Detectable amount. 


\section{Skin Layer Formation on the Etched Trench Walls}

Another interesting observation was the formation of a few $100 \mathrm{~nm}$ thick layer on the side walls of the etched trenches. This layer could be readily stripped in nickel TFB etchant (Transene ${ }^{\mathrm{TM}}$ ) but was inert in nickel Type 1 etchant (Transene ${ }^{\mathrm{TM}}$ ). The study on skin layer composition and formation is currently being studied but is likely related to the reaction of the nickel masking layer with the etch gases.

\section{CONCLUSION}

In this report, a specially modified ICP-RIE etch tool using $\mathrm{NF}_{3}$ and $\mathrm{H}_{2} \mathrm{O}$ gas chemistry for glass etching is presented. Instead of conventionally feeding gases through the ICP source, a stainless steel gas diffuser ring on the metal plate of the mechanical clamping plate of the etcher has been incorporated to supply $\mathrm{NF}_{3}$ and $\mathrm{H}_{2} \mathrm{O}$ vapor gases. $2000 \mathrm{~W}$ source power and $400 \mathrm{~W}$ substrate power for novel $\mathrm{SF}_{6} / \mathrm{NF}_{3} / \mathrm{H}_{2} \mathrm{O}$ plasma based etching has been explored. An etch rate of $0.81 \mu \mathrm{m} / \mathrm{min}$ and $0.68 \mu \mathrm{m} / \mathrm{min}$ was obtained for quartz and borosilicate wafers respectively. Comparison between $\mathrm{SF}_{6} / \mathrm{NF}_{3} / \mathrm{H}_{2} \mathrm{O}$ etching and conventional single $\mathrm{SF}_{6}$ etching was undertaken on both borosilicate and quartz glass. Initial results on the etch rate, surface roughness and selectivity of $\mathrm{SF}_{6} / \mathrm{NF}_{3} / \mathrm{H}_{2} \mathrm{O}$ based ring diffuser etching suggest that the etching mechanism is clearly shifted from physical etching to chemically dominated etching. AFM scans have shown unprecedented ultra-smooth surface roughness (Ra) as $\sim 6 \AA$ at 0.81 $\mu \mathrm{m} / \mathrm{min}$ etching rate for quartz.

\section{ACKNOWLEDGEMENTS}

This work was supported in part by the DARPA under U.S. Army Research Office Grant W31P4Q-13-1-002 and Corning Inc. GH acknowledges partial support from Scientific and Technical Research Council of Turkey (TUBITAK) for a 2213-International $\mathrm{PhD}$. Fellowship Program. The use of facilities at the PSU Site of the NSF National Nanotechnology Infrastructure Network (NNIN) under Agreement 0335765 is acknowledged.

\section{CONTACT}

S. Tadigadapa: Tel. (814) 865 2730, sat10@psu.edu

\section{REFERENCE}

[1] S. Karecki, R. Chatterjee, L. Pruette, R. Reif, T. Sparks, L. Beu, V.Vartanian, K. Novoselov, J. Electrochem. Soc. 148 (2001) 141.

[2] S.S. Choi, D.W. Kim, M.J. Park, J. Korean Phys. Soc. 45 (2004)1500.

[3] C.-H. Yang, C.-M. Dai, in: Proceedings of the SPIE - The International Society for Optical Engineering Optical Microlithogra-phy XI, 25-27 February 1998, 3334, 1998, p. 553.

[4] F.H. Bell, O. Joubert, G.S. Oehrlein, Y. Zhang, D. Vender, J. Vac.Sci. Technol. A (Vac. Surf. Films) 12 (1994) 3095.

[5] G. Adegboyega, I. PerezQuintana, A. Poggi, E. Susi, M. Merli, J.Vac. Sci. Technol. B 15 (1997) 623.

[6] C.H. Lin, G.B. Lee, Y.H. Lin, G.L. Chang, J. Micromech. Microeng. 11 (2001) 726.

[7] X.H. Li, T. Abe, M. Esashi, Sensor Actuat. a - Phys. 87 (2001) 139.

[8] Li, L., T. Abe, and M. Esashi, Smooth surface glass etching by deep reactive ion etching with $\mathrm{SF}_{6}$ and $\mathrm{Xe}$ gases. Journal of Vacuum Science \& Technology B (Microelectronics and Nanometer Structures), 2003. 21(6): p. 2545.
[9] Goyal, A., V. Hood, and S. Tadigadapa, High speed anisotropic etching of Pyrex for microsystems applications. Journal of Non-Crystalline Solids, 2006. 352(6-7): p. 657.

[10] Queste, S., et al., Manufacture of microfluidic glass chips by deep plasma etching, femtosecond laser ablation, and anodic bonding. Microsystem Technologies, 2010. 16(8-9): p. 1485-1493.

[11] Wolf, S. and Tauber, R, Silicon processing for the VLSI Era, Volume 1: processing technology, Lattice Press, California 